\section{Conceptual framework for establishing the African Stroke Organization}

International Journal of Stroke 2021, Vol. 16(1) 93-99 (C) 2020 World Stroke Organization Article reuse guidelines: sagepub.com/journals-permissions DOI: $10.1177 / 1747493019897871$ journals.sagepub.com/home/wso @SAGE

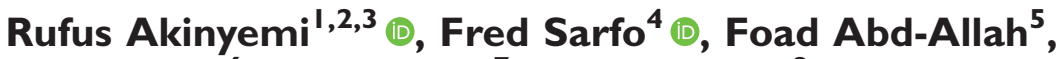 \\ Yomi Ogun 6 , Mofou Belo ${ }^{7}$, Patty Francis ${ }^{8}$, \\ M Bettencourt Mateus 9 , Kathleen Bateman ${ }^{10}{ }_{(\mathbb{D}}$, \\ Pamela Naidoo "', Augustina Charway-Felli ${ }^{12}$, Albert Akpalu ${ }^{13}$, \\ Kolawole Wahab ${ }^{14}$, Christian Napon ${ }^{15}$, Oyedunni Arulogun ${ }^{16}$, \\ Ad Adams Ebenezer ${ }^{17}$, Gloria Ekeng ${ }^{18}$, George Scola ${ }^{19}$, \\ Kolapo Hamzat ${ }^{20}$, Stanley Zimba ${ }^{21}$, Paul Macaire Ossou-Nguiet ${ }^{22}$, \\ Julius Ademokoya ${ }^{23}$, Philip Adebayo ${ }^{24}$, \\ Biniyam Alemayehu Ayele ${ }^{25}$, Deise Catamo $\mathrm{Vaz}^{26}$, \\ Godwin Ogbole ${ }^{27}$, Patrice Barasukan ${ }^{28}$, Rita Melifonwu ${ }^{29} \mathbb{D}_{\text {, }}$ \\ Ikenna Onwuekwe ${ }^{30}$, Sarah Belson ${ }^{31}$, Albertino Damasceno ${ }^{32}$, \\ Njideka Okubadejo ${ }^{33}$, Alfred K Njamnshi ${ }^{34}$, Julius Ogeng'o ${ }^{35}$, \\ Richard W Walker ${ }^{36}$, Amadou Gallo Diop ${ }^{37}$, Adesola Ogunniyi ${ }^{1,3}$, \\ Rajesh Kalaria ${ }^{38}$, Peter Sandercock ${ }^{39}$ (D), Stephen Davis ${ }^{40}$, \\ Michael Brainin ${ }^{4}$, Bruce Ovbiagele ${ }^{42}$ and Mayowa Owolabi ${ }^{2,3,43}$
}

'Institute for Advanced Medical Research and Training, College of Medicine, University of Ibadan, Ibadan, Nigeria

${ }^{2}$ Centre for Genomic and Precision Medicine, College of Medicine, University of Ibadan, Ibadan, Nigeria

${ }^{3}$ Division of Neurology, Department of Medicine, College of Medicine, University of Ibadan, Ibadan, Nigeria

${ }^{4}$ Kwame Nkrumah University of Science \& Technology, Kumasi, Ghana; Komfo Anokye Teaching Hospital, Kumasi, Ghana

${ }^{5}$ Department of Neurology, Cairo University Hospital, Cairo, Egypt

${ }^{6}$ Department of Internal Medicine/Neurology, Lagos State University, Lagos, Nigeria

${ }^{7}$ Department of Neurology, Sylvanus Olympio University Teaching Hospital, Lomé, Togo

${ }^{8}$ Stroke Unit, Umhlanga Medical Centre, Umhlanga Rocks, South Africa ${ }^{9}$ Department of Neurology, Hospital Américo Boavida-University Agostinho Neto, Luanda-Angola

${ }^{10}$ Stroke Unit, Neurology Division, Department of Medicine, University of Cape Town, Groote Schuur Hospital, Cape Town, South Africa

"Heart and Stroke Foundation South Africa/University of the Western Cape, Cape Town, South Africa

${ }^{12}$ Neurology Department, 37 Military Hospital, Accra, Ghana

${ }^{13}$ Korle Bu Teaching Hospital, Accra, Greater Accra Region, Ghana

${ }^{14}$ Neurology Unit, Department of Medicine, Faculty of Clinical Sciences, University of Ilorin, llorin, Nigeria

${ }^{15}$ Department of Neurology, Bogodogo University Hospital, Ouagadougou, Burkina Faso

${ }^{16}$ Department of Health Promotion and Education, College of Medicine, University of Ibadan, Ibadan, Nigeria

${ }^{17}$ Stroke Association Support Network-Ghana (SASNET-GHANA), Accra, Ghana

${ }^{18}$ Stroke Care International, Lagos, Nigeria

${ }^{19}$ The Stroke Survivors Foundation, Johannesburg, South Africa

${ }^{20}$ Department of Physiotherapy, College of Medicine, University of Ibadan, Ibadan, Nigeria
${ }^{21}$ Department of Internal Medicine, University Teaching Hospital, Lusaka, Zambia

${ }^{22}$ Department of Neurology and Stroke Unit, University Hospital of Brazzaville, Congo

${ }^{23}$ Department of Special Education, University of Ibadan, Ibadan, Nigeria

${ }^{24}$ Aga Khan University, East Africa /Aga Khan Hospital, Dar es Salaam, Tanzania

${ }^{25}$ Department of Neurology, College of Health Science, Addis Ababa University, Addis Ababa, Ethiopia

${ }^{26}$ Division of Neurology, Department of Medicine, Central Hospital of Maputo, Maputo, Mozambique

${ }^{27}$ Department of Radiology, University College Hospital; Department of Radiology, University of Ibadan, Ibadan, Nigeria

${ }^{28}$ Department of Neurology, University Teaching Hospital of Kamenge, University of Burundi, Bujumbura, Burundi

${ }^{29}$ Stroke Action Nigeria, Ime Obi Ogbeoza, Onitsha, Nigeria

${ }^{30}$ Neurology Unit, Department of Medicine, University of Nigeria Teaching Hospital, Ituku- Ozalla, Enugu, Nigeria. Department of Medicine, College of Medicine, University of Nigeria, Enugu Campus, Nigeria

${ }^{31}$ World Stroke Organization, Geneva, Switzerland/ Stroke Association, London, United Kingdom

${ }^{32}$ Department of Cardiology, Faculty of Medicine, Eduardo Mondlane University, Maputo, Mozambique

${ }^{33}$ Neurology Unit, Department of Medicine, College of Medicine/Lagos University Teaching Hospital, Idi Araba, Lagos, Nigeria

${ }^{34}$ Department of Neurology, Yaoundé Central Hospital \& Faculty of Medicine and Biomedical Sciences, University of Yaoundé I, Yaoundé, Cameroon; Brain Research Africa Initiative (BRAIN), Geneva, $\mathrm{CH} /$ Yaoundé, Cameroon

${ }^{35}$ Department of Human Anatomy, University of Nairobi, Nairobi, Kenya ${ }^{36}$ Department of Medicine, North Tyneside General Hospital, Rake Lane, North Shields, Tyne and Wear, UK

${ }^{37}$ Clinique Neurologique, C.H.U. Fann, Dakar, Senegal

${ }^{38}$ Institute of Neuroscience, Newcastle University, Campus for Ageing and Vitality, Newcastle upon Tyne, UK 


\begin{abstract}
Africa is the world's most genetically diverse, second largest, and second most populous continent, with over one billion people distributed across 54 countries. With a $23 \%$ lifetime risk of stroke, Africa has some of the highest rates of stroke worldwide and many occur in the prime of life with huge economic losses and grave implications for the individual, family, and the society in terms of mental capital, productivity, and socioeconomic progress. Tackling the escalating burden of stroke in Africa requires prioritized, multipronged, and inter-sectoral strategies tailored to the unique African epidemiological, cultural, socioeconomic, and lifestyle landscape. The African Stroke Organization (ASO) is a new pan-African coalition that brings together stroke researchers, clinicians, and other health-care professionals with participation of national and regional stroke societies and stroke support organizations. With a vision to reduce the rapidly increasing burden of stroke in Africa, the ASO has a four-pronged focus on (I) research, (2) capacity building, (3) development of stroke services, and (4) collaboration with all stakeholders. This will be delivered through advocacy, awareness, and empowerment initiatives to bring about people-focused changes in policy, clinical practice, and public education. In the spirit of the African philosophy of Ubuntu "I am because we are," the ASO will harness the power of diversity, inclusiveness, togetherness, and team work to build a strong, enduring, and impactful platform for tackling stroke in Africa.
\end{abstract}

\title{
Keywords
}

Stroke, organization, conceptual framework, Africa

Received: 31 October 2019; accepted: I4 November 2019

\section{Introduction}

Africa is the world's most genetically diverse, second largest, and second most populous continent, with over one billion people distributed across 54 countries. Africa is currently experiencing an epidemiologic transition and double burden of disease driven by population aging, changes in dietary habits, physical inactivity, and increased vascular risk factors (especially hypertension, diabetes mellitus and obesity) while infectious diseases persist. Persons living with HIV/AIDS develop accelerated aging and heightened cardiovascular risks while low awareness, underdetection, under-treatment, and poor control of cerebrovascular risk factors further complicate the picture in a milieu of scarce resources for health and healthcare services. Stroke is a leading cause of disability, death, and dementia worldwide. ${ }^{1}$ Africa, in particular, has some of the highest rates of stroke worldwide, with an annual stroke incidence rate up to 316 per 100,000, a prevalence rate up to 1460 per 100,000 , and three-year fatality rate up to $84 \% .^{2-5}$ Data to estimate the lifetime risk of stroke among Africans are limited but it is likely to be higher than the $23 \%$ suggested in a recent analysis of the Global Burden of Disease Study (global average: $25 \%) .{ }^{6}$ Health data management systems are poor across Africa and many people affected by stroke live in hard to reach communities. Stroke leads to both tangible and intangible economic losses and many Africans are struck in the prime of life, during their productive paid working life, with grave implications for the individual, family, and society in terms of mental capital, productivity, and socioeconomic progress. ${ }^{4,7}$ Stroke research productivity is low in Africa. ${ }^{4}$
Multidisciplinary teams and effective systems of care are also sorely lacking. ${ }^{8}$ Tackling the burden of stroke in Africa requires prioritized, multipronged, and intersectoral strategies tailored to the unique African epidemiological, cultural, socioeconomic, and lifestyle landscape. ${ }^{2,4,8-15}$

\section{A great need}

There is an urgent need for a framework that will bring together African stroke clinicians and researchers along with other stroke health-care professionals and trainees, national and regional societies, and stroke support organizations (SSOs). Africa needs a platform to synchronize capacity building and professional development, organization and harmonization of care and relevant research together with effective advocacy and engagement with care providers, stroke survivors, the lay community, policy makers, and governments in order to "favorably bend" the growing curve of

\footnotetext{
${ }^{39}$ Centre for Clinical Brain Sciences, University of Edinburgh, Edinburgh, UK

${ }^{40}$ National Stroke Research Institute, Austin Hospital, University of Melbourne, Melbourne, Victoria, Australia

${ }^{41}$ Department of Clinical Neurosciences and Preventive Medicine, Danube University Krems, Krems, Austria

${ }^{42}$ Department of Neurology, University of California, San Francisco, USA

${ }^{43}$ Blossom Specialist Medical (Neurorehabilitation) Center, Ibadan, Nigeria

Corresponding author:

Rufus Akinyemi, Neuroscience and Ageing Research Unit, Institute for Advanced Medical Research and Training, College of Medicine, University of Ibadan, Ibadan, Nigeria.

Email: rufusakinyemi@yahoo.com
} 
Figure I. ASO Conceptual Framework: The African map with a rich mosaic of a colourful network represents the rich genetic, cultural and geographical diversity in Africa. The interconnectivities represent the neuronal network of the brain. The interconnected individuals represents the African Ubuntu Philosophy of inclusiveness, cooperation and collaboration. The middle layer depicts the four core pillars of ASO activities: stroke research, capacity building programmes, development of stroke services and promotion of stroke awareness, advocacy and empowerment of stroke survivors, and their families and caregivers. The outer layer represents other core values of ASO: working with Partners to actualize People - focused positive changes in Policies and Practice in the science and practice of Stroke in the African region.

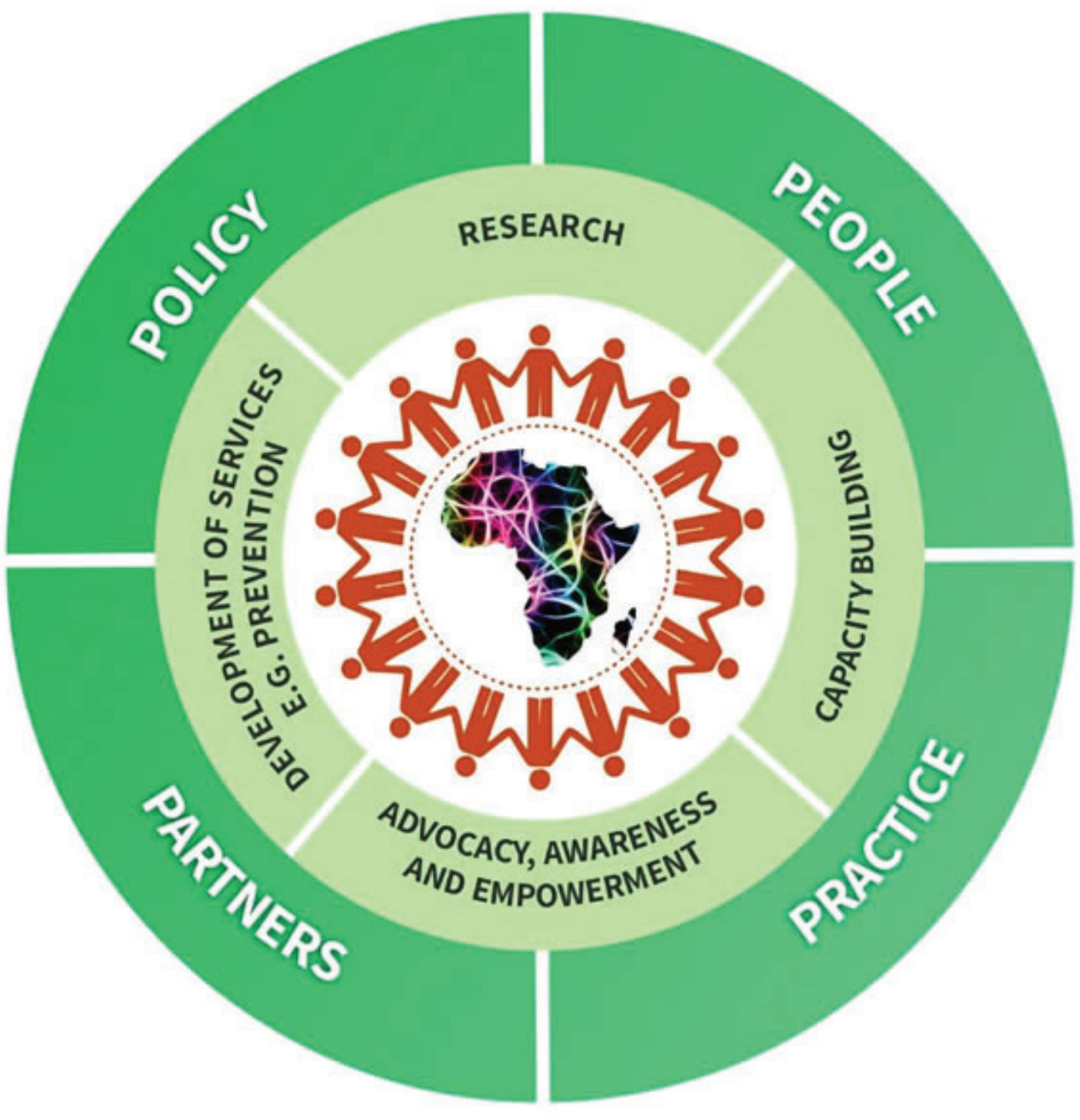

\section{ASO CONCEPTUAL FRAMEWORK}

stroke and reduce its impact on Africans. It is now absolutely necessary and crucial to evolve a multilevel, multipronged, and multistrategic approach to engage with relevant cultural, economic, political, and professional blocks in Africa and beyond and get stroke prioritized on the development agenda for Africa. We need to also create awareness among key stakeholders including the private and public sectors. 
Thus, we need a platform that will facilitate engagement with the African Union (AU), the World Bank, New Partnership for Africa's Development, and the World Health Organization (WHO) for a more proactive and more effective focus on stroke in Africa. The time is now, if Africa will be saved from the devastating individual, family, and societal impact of stroke and progress will be made towards the actualization of the Sustainable Development Goal 3 which is aimed to "ensure healthy lives and promote wellbeing..." and reduce premature death from non-communicable diseases (NCDs) including stroke by $33 \%$ by year 2030 .

\section{Historical development}

There have been previous pockets of efforts in the last two decades to create regional stroke platforms in Africa. In 2004, the Franco-African League against Stroke was established among francophone African countries and has since run regular programs of advocacy and stroke education including an annual stroke meeting. In September 2010, participants at the first East African Neuroscience Conference in Nairobi, Kenya also discussed the need and possibility of creating an African Stroke Society. The origin of the African Stroke Organization (ASO), the first pan-African stroke initiative, dates back to 5 October 2016 when the concept document for its establishment was first developed and forwarded to the leadership of the World Stroke Organization (WSO) and other leaders in the stroke community. The idea was extremely well received and supported. Together with other leaders, efforts have subsequently been made to secure funding support to convene a strategic leaders' synergium $^{15}$ and the first African stroke conference ${ }^{16}$ in a bid to bring together diverse individuals and groups for real engagement that will change the stroke narrative in Africa.

The ASO aspires to be an effective and true panAfrican society of stroke researchers, clinicians, other health-care professionals, and stroke survivors with support from national and regional stroke societies and SSOs with passion for, and commitment to, stroke care, research, education, and advocacy. The primary goal is to reduce the escalating burden of stroke and its short- and long-term consequences on the people of Africa. The ASO will further anchor activities of the global Stroke Control Observatory and burden Reduction Ecosystem for Africa as part of the WSO-Lancet Neurology Commission on stroke in low- and middle-income countries. ${ }^{17}$

The concept of the vision, mission, and core programs is set out in Figure 1. However, further consultation on these elements will be sought in the operational planning stage from a wider range of stakeholders from across Africa and involving disciplines related to cerebrovascular diseases.

\section{Vision}

The vision of the ASO is "reducing the burden of stroke in Africa." While in tandem with the vision of the WSO, it is "Afrocentric" focusing on the specific issues in, and needs of Africa.

\section{Mission}

The Mission is

to reduce the burden of stroke in Africa through multidisciplinary research and capacity building, promoting the development of effective stroke prevention and intervention services, enhancing stroke awareness, advocating for stroke survivors and their families/caregivers and driving the formulation of stroke-friendly policies across multiple levels of policy making in African nations.

\section{Core areas of focus}

1. Research: Stroke epidemiologic surveillance, regional/national stroke registries, genomic and transomics epidemiology for discovery and translation of novel diagnostics and therapeutics, clinical trials across the trajectory of stroke care, stroke prevention, post-stroke vascular cognitive impairment, post-stroke outcomes, quality of life, stroke services research, stroke recovery and rehabilitation, community care of stroke, etc.

2. Capacity building: Multidisciplinary stroke care providers (physicians, surgeons, nurses, physiotherapists, pharmacists, laboratory scientists, speech and language therapists, occupational therapists, clinical psychologists, dietitians, social workers, and health educators).

3. Development of stroke services (stroke quadrangle ${ }^{18}$ ): Surveillance, prevention, hyperacute and acute care, rehabilitation and recovery including care programs for survivors and caregivers, and community-based care of stroke survivors and volunteer workers.

4. Advocacy, awareness, empowerment, and collaboration: Engagement across the continuum of the socio-ecological framework including individuals, family, community, and government (patients, care providers, payers, populace, policy makers, implementation partners, e.g. African Academy of Sciences, AU, International Society of Hypertension, World Hypertension League, WHO, 
NCD Alliance, Global Neurology Alliance, Global Rehabilitation Alliance, and similar bodies). Engagement with community and religious leaders as well as traditional medicine practitioners is particularly important in order to effectively deal with the peculiar anthropological and sociocultural perspectives influencing stroke care in Africa.

\section{Relationship with the WSO and other stroke and brain-related organizations}

The ASO will be an affiliate/member of the WSO and aspires to work with other global, continental, and national stroke and brain-related organizations such as the Global Brain Health Institute, World Federation of Neurology, World Federation for Neurorehabilitation, Alzheimer's Association, International Society for Vascular Behavioural and Cognitive Disorders, American Heart Association/American Stroke Association (AHA/ASA), European Stroke Organization (ESO), Canadian Stroke Network (CSN), African Academy of Neurology (AFAN), Society of Neuroscientists of Africa, American Academy of Neurology, European Academy of Neurology, and others to draw inspiration, useful lessons, and support for her rapid growth and sustainability.

\section{Proposed organizational structure}

\section{Steering committee}

The ASO is appointing a steering committee to provide strategic direction and be responsible for the everyday activities of the ASO. This committee will also exercise authority in the management of the business and affairs of the ASO during intervals between meetings. The steering committee shall consist of a chair, co-chair, past chair, secretary, treasurer, regional coordinators representing the five regions of Africa (North, West, South, East, and Central), a representative of SSOs, and a representative of early career stroke professionals.

\section{Advisory board}

The board will consist of individuals who are clinicians, research leaders, allied health professionals, people affected by stroke, and professional leaders of international repute in the field of cerebrovascular disorders. They shall include individuals from within and outside Africa who have particularly demonstrated commitment to the building of human capacity, infrastructural development, research leadership, development of stroke services, and advocacy for the prevention, diagnosis, and treatment of cerebrovascular disorders in
Africa. The membership will include Africans who are already on the board of the WSO, regional representatives, a representative of the AFAN, and representatives of national stroke societies, stroke survivors, SSOs, and professional groups relevant to stroke management. International leaders and African diaspora with demonstrable evidence of promoting the ideals of the ASO shall also be eligible to be nominated to the board of ASO.

\section{Committees/working groups/professional interest areas}

ASO members shall have opportunities to express themselves and work collaboratively in committees, working groups, and professional interest areas. Each committee/working group shall have a chair and cochair to provide leadership in line with the terms of reference of the committee.

\section{Membership}

Membership is proposed to consist of two categories: corporate and individual. The corporate members shall consist of national stroke societies, SSOs, and industry/ pharmaceutical companies. The individual members shall include fellows, regular, associate, honorary, and junior (student) members.

\section{Proposed programs}

\section{Stroke research}

Research projects may be in any area of basic, clinical, translational, prevention, control, behavioral, and/or population research. Collaborations among investigators are encouraged to develop research programs in translational stroke research and implementation science including but not limited to capacity building, task-shifting/task-sharing strategies, organization of stroke services, stroke registers, stroke prevention (primary and secondary), stroke epidemiology, imaging, proteomics and genomics, and research focusing on pediatric, adolescent, and young adult strokes including sickle cell disease and stroke. ${ }^{19,20}$ ASO shall be interested in developing educational, outreach, and research projects leading to increased biospecimen collection from African populations, a critical endeavor to potentially elucidate the biological factors associated with stroke health disparities. Joint research projects conducted primarily in African institutions may be in any area of stroke research. These projects may focus, for example, on general areas of stroke epidemiology and/ or behavioral, metabolic, and environmental issues related to stroke prevention, treatment, and control. 
These efforts should be aimed at eventually securing competitively funded research awards. Small grants are desirable to encourage career development of early stage investigators.

\section{Capacity building and training}

Training programs that link the faculty and students of the partner institutions are among the most productive ways to sustain long-term effective partnerships. These programs must emphasize two aspects: (a) the training of African stroke professionals, investigators, and students and (b) the recognition and understanding of the issues and problems associated with stroke disparities in Africa and people of African ancestry. Research training should cover basic, clinical, translational, behavioral, and population research, with due attention to the cultural sensitivities of the African society. Virtual training as offered by the World Stroke Academy and annual African Stroke Medicine Course with support from the WSO, ESO, AHA/ASA, CSN, AFAN, and similar established stroke organizations will be highly beneficial in raising the necessary multidisciplinary manpower to improve stroke outcomes and strengthen stroke prevention in Africa.

\section{Stroke services development}

The WSO Global Stroke Services Guidelines and Action Plan ${ }^{21}$ constitutes an extremely useful template for developing stroke services in Africa, a region with limited health-care resources. Despite differences in resource availability across the continent, the WSO advocates that stroke awareness, education, prevention, and treatment should always be feasible. The ASO will support regional and national societies to develop pragmatic guidelines, establish benchmarks, and set goals for continuous expansion and improvement of their stroke service capabilities. The WSO Global Stroke Services Guidelines and Action Plan ${ }^{21}$ is a synopsis of the core recommendations and quality indicators adapted from 10 high-quality multinational stroke guidelines. It can be used to establish the current level of stroke services, target goals for expanding stroke resources, and ensuring that all stages of stroke care are being adequately addressed. The ASO will facilitate the implementation of this guideline statement across the continent. The ASO will also support innovations in stroke services that are relevant to resource-limited populations of Africa including partnerships with organizations in high-income countries. The very successful Wessex-Ghana Stroke Partnership funded by the Tropical Health \& Education Trust program of the UK Department for International Development is an excellent model showing the feasibility of north- south partnerships in enhancing stroke care in Africa. ${ }^{22,23}$

\section{Advocacy, awareness, empowerment, and collaboration}

Working with the World Stroke Campaign Committee and the SSO Committee of the WSO and adapting the plethora of awareness and advocacy materials and instruments already available and developing new ones, the ASO will focus efforts at improving stroke literacy and correcting attitudes to and perceptions of stroke within the African cultural milieu. ${ }^{12,13,24-26}$ Stroke education across the life span with programs of engagement involving school children, inclusion of stroke education in school curricula, engagement with faith-based organizations, and community leaders and gatekeepers are absolutely important in Africa. Specific periods of the year will be dedicated to advocacy and awareness across African countries based on consensus. Advocacy with policy makers and governments will seek improved funding for stroke research, prevention, care, and rehabilitation programs.

In order to develop a strategic action plan for the implementation of the programs of ASO, a synergium ${ }^{15}$ is anticipated very early in the life of the organization. This will be a face-to-face meeting of key stakeholders that will devise a prioritized agenda for stroke in Africa focusing on each of the thematic areas, set targets, and craft pragmatic action plans towards the year 2030. The outputs from this meeting will constitute the blueprints of the programs of the ASO which will drive the agenda to accelerate progress in stroke science, care, services, education, and advocacy in Africa. These will be widely disseminated through publications in reputable journals, conferences, blogs, and social media platforms. Annual or biennial African regional stroke conferences are anticipated subsequently. ${ }^{16} \mathrm{We}$ anticipate that the programs of ASO will be funded through membership fees, sponsorships, and philanthropic support.

\section{Conclusion}

We present a conceptual framework for the ASO, a veritable platform for fighting the escalating burden of stroke in Africa. This sets the vision of ASO in the public domain so that every interested person can appreciate and run with the vision and find their place in the synergy of efforts that will culminate in reducing the growing burden of stroke in Africa. ASO will be people - focused and work with relevant regional and global partners to influence policies and practice as regards stroke and other cerebrovascular disorders. In the spirit of the African philosophy of Ubuntu "I am because we are" (from Southern Africa) 
which emphasizes the power of diversity, inclusiveness, togetherness, and team work, we invite all hands to be on deck to add "precept by precept and line upon line" to the building blocks of a strong, enduring and impactful ASO in Africa, and for Africa.

\section{Declaration of conflicting interests}

The author(s) declared no potential conflicts of interest with respect to the research, authorship, and/or publication of this article.

\section{Funding}

The author(s) received no financial support for the research, authorship, and/or publication of this article.

\section{ORCID iDs}

Rufus Akinyemi (D) https://orcid.org/0000-0001-5286-428X Fred Sarfo (1) https://orcid.org/0000-0001-7274-5093

Kathleen Bateman (D) https://orcid.org/0000-0002-0213-7102 Rita Melifonwu (D) https://orcid.org/0000-0002-5192-3871

Peter Sandercock (D) https://orcid.org/0000-0001-8484-0135

\section{References}

1. Feigin VL, Roth GA, Naghavi M, et al. Global burden of stroke and risk factors in 188 countries, during 19902013: a systematic analysis for the Global Burden of Disease Study 2013. Lancet Neurol 2016; 15: 913-924.

2. Walker R, Whiting D, Unwin N, et al. Stroke incidence in rural and urban Tanzania: a prospective, communitybased study. Lancet Neurol 2010; 9: 786-792.

3. Ezejimofor MC, Uthman OA, Maduka O, et al. Stroke survivors in Nigeria: a door-to-door prevalence survey from the Niger Delta region. J Neurol Sci 2017; 372: 262-269.

4. Owolabi MO, Akarolo-Anthony S, Akinyemi R, et al. The burden of stroke in Africa: a glance at the present and a glimpse into the future. Cardiovasc J Afr 2015; 26: S27-S38.

5. Akinyemi RO, Owolabi MO, Ihara M, et al. Stroke, cerebrovascular diseases and vascular cognitive impairment in Africa. Brain Res Bull 2019; 145: 97-108.

6. LRoS Collaborators GBD 2016, Feigin VL, Nguyen G, et al. Global, regional, and country-specific lifetime risks of stroke, 1990 and 2016. N Eng J Med 2018; 379: 2429-2437.

7. Owolabi MO, Sarfo F, Akinyemi R, et al. Dominant modifiable risk factors for stroke in Ghana and Nigeria (SIREN): a case-control study. Lancet Glob Health 2018; 6: e436-e46.

8. Akinyemi RO and Adeniji OA. Stroke care services in Africa: a systematic review. J Stroke Med 2018; 1: 55-64.

9. Feigin VL and Krishnamurthi R. Stroke is largely preventable across the globe: where to next? Lancet 2016; 388: 733-734.

10. Feigin VL, Krishnamurthi R, Bhattacharjee R, et al. New strategy to reduce the global burden of stroke. Stroke 2015; 46: 1740-1747.
11. Jenkins C, Arulogun OS, Singh A, et al. Stroke investigative research and education network: community engagement and outreach within phenomics core. Health Educ Behav 2016; 43: 82S-92S.

12. Akinyemi RO, Ogah OS, Ogundipe RF, et al. Knowledge and perception of stroke amongst hospital workers in an African community. Eur J Neurol 2009; 16: 998-1003.

13. Akinyemi RO, Owolabi LF, Owolabi MO, Akinyemi JO and Ogunniyi A. Perception of stroke among a sample of urban dwellers in Southwestern Nigeria: a preliminary report. Neurology 2008; 70: A17-A8.

14. Akinyemi RO, Owolabi MO, Adebayo PB, et al. Taskshifting training improves stroke knowledge among Nigerian non-neurologist health workers. J Neurol Sci 2015; 359: 112-116.

15. Hachinski V, Donnan GA, Gorelick PB, et al. Stroke: working toward a prioritized world agenda. Stroke 2010; 41: 1084-1099.

16. Owolabi M, Sarfo FS, Akinyemi R, Gebreyohanns M and Ovbiagele B. The Sub-Saharan Africa Conference on Stroke (SSACS): an idea whose time has come. J Neurol Sci 2019; 15: 194-198.

17. Owolabi M, Johnson W, Khan $\mathrm{T}$ and Feigin V. Effectively combating stroke in low- and middle-income countries: placing proof in pragmatism - The Lancet Neurology Commission. J Stroke Med 2018; 1: 65-67.

18. Owolabi MO. Taming the burgeoning stroke epidemic in Africa: stroke quadrangle to the rescue. West Indian Med $J$ 2011; 60: 412-421.

19. Ruffieux N, Njamnshi AK, Wonkam A, et al. Association between biological markers of sickle cell disease and cognitive functioning amongst Cameroonian children. Child Neuropsychol 2013; 19: 143-160.

20. Noubiap JJ, Mengnjo MK, Nicastro N and KamtchumTatuene J. Neurologic complications of sickle cell disease in Africa: a systematic review and meta-analysis. Neurology 2017; 89: 1516-1524.

21. Lindsay P, Furie KL, Davis SM, Donnan GA and Norrving B. World Stroke Organization global stroke services guidelines and action plan. Int J Stroke 2014; 9: 4-13.

22. Gould A, Asare H, Akpalu A, et al. Development of stroke care in Ghana. Int J Stroke 2011; 6: 150-151.

23. Johnson L, Akpalu A, Anane D, et al. Multi-disciplinary stroke care in developing countries - lessons from the Wessex-Ghana Stroke Partnership. South Sudan Med J 2017; 10: 84-86.

24. Hertz JT, Madut DB, William G, Maro VP, Crump JA and Rubach MP. Perceptions of stroke and associated health-care-seeking behavior in Northern Tanzania: a community-based study. Neuroepidemiology 2019; 53: $41-47$.

25. Jenkins C, Ovbiagele B, Arulogun O, et al. Knowledge, attitudes and practices related to stroke in Ghana and Nigeria: a SIREN call to action. PLoS One 2018; 13: e0206548.

26. Akinyemi RO, Sarfo FS, Akinyemi J, et al. Knowledge, attitudes and practices of West Africans on genetic studies of stroke: evidence from the SIREN Study. Int $J$ Stroke 2019; 14: 69-79. 